\title{
Cardiac biomarkers in the intensive care unit
}

\author{
Anthony S McLean ${ }^{*}$ and Stephen J Huang
}

\begin{abstract}
Cardiac biomarkers (CB) were first developed for assisting the diagnosis of cardiac events, especially acute myocardial infarction. The discoveries of other $C B$, the better understanding of cardiac disease process and the advancement in detection technology has pushed the applications of CB beyond the 'diagnosis' boundary. Not only the measurements of $C B$ are more sensitive, the applications have now covered staging of cardiac disease, timing of cardiac events and prognostication. Further, $C B$ have made their way to the intensive care setting where their uses are not just confined to cardiac related areas. With the better understanding of the CB properties, CB can now help detecting various acute processes such as pulmonary embolism, sepsis-related myocardial depression, acute heart failure, renal failure and acute lung injury. This article discusses the properties and the uses of common $\mathrm{CB}$, with special reference to the intensive care setting. The potential utility of "multimarkers" approach and microRNA as the future $\mathrm{CB}$ are also briefly discussed.
\end{abstract}

\section{Introduction}

Blood cardiac biomarkers (CB) have become increasingly accurate for evaluating cardiac abnormalities during the past 40 years. Initially, with the focus on myocardial infarction (MI), the use of creatinine kinase-MB (CKMB), first described in 1972, was a major step forward in the development of a highly cardiac-specific biomarker. The introduction of cardiac troponin (cTn) assays in 1989 was the next major advance, and subsequent refinement of the assays now has the definition of acute myocardial infarction (AMI) centered on it. This progression ironically has brought considerable difficulties to the critical care physician who deals with multiorgan failure rather than the patient presenting to the emergency department with chest pain or single-organ pathology. The recent penetration of high-sensitivity (hs) cTn, replacing the fourth-generation cTn assays further compounds these diagnostic challenges.

Moving beyond a sole focus on MI, the search for alternative and supplementary serum markers to assist in unravelling the presence, severity, and type of cardiac injury has been intense (Figure 1). Whilst cardiac ischemia/infarction is the most prevalent cause of cardiac injury with biomarker development reflecting this, the search for more meaningful biomarkers now includes $\mathrm{CB}$ for inflammatory processes and myocardial wall

\footnotetext{
* Correspondence: anthony.mclean@sydney.edu.au

Department of Intensive Care Medicine, Nepean Hospital, Sydney Medical School, Penrith, NSW 2750, Australia
}

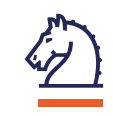

stress (as a result of pressure or volume overload) where evaluation extends beyond myocardial necrosis. The important role of $\mathrm{C}$-reactive protein (CRP) as a prognostic marker is an example of the former while natriuretic peptides are now accepted as clinically useful markers of cardiac stress.

In the critical care setting, the challenge of confounding factors brings about interpretation difficulties. Clarity in diagnosis and/or guidance for management frequently present when the heart is the only organ affected, such as in the emergency department or cardiology ward, does not always hold in the intensive care unit (ICU) setting. Even so, an understanding of the commonly used $\mathrm{CB}$ can be very helpful for cardiac evaluation of the critically ill patient.

\section{Classes of cardiac biomarkers}

The search for clinically useful CB has resulted in a large number of circulating plasma substances being investigated. These can be broadly grouped temporally into three major categories: inflammatory, acute muscle injury, and cardiac stress (Figure 2).

Biomarkers for inflammatory processes

Cardiac wound healing after MI can be divided into four phases: phase 1 begins with the actual death of myocytes commencing within 6 hours and continuing for up to 4 days; the phase 2 is that of an inflammatory response beginning 12-16 hours after onset of ischemia; phase 3 is when granulation tissue begins forming at the infarct 


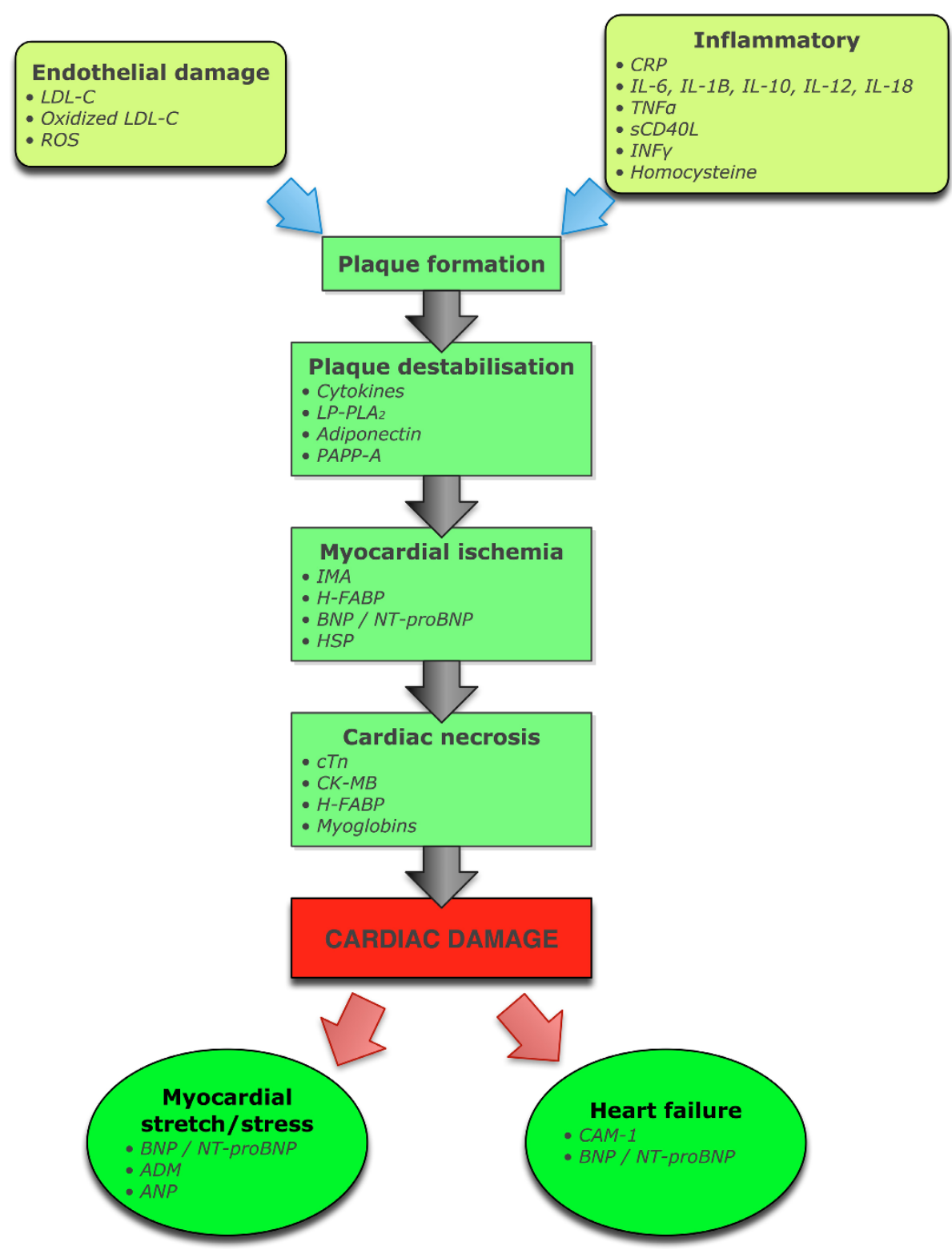

Figure 1 The development of cardiac biomarkers. ADM, adrenomedullin; BNP, B-type natriuretic peptide; CAM, cell adhesion molecule; CK$M B$, creatine kinase-MB; CRP, C-reactive protein; CTn, cardiac troponin; H-FABP, human fatty-acid binding protein; HSP, heat shock protein; IL, interleukin; IMA, ischemia-modified albumin; INF , interferon $\gamma$; LP-LPA , lipoprotein-associated phospholipase A2; PAPP, pregnancy-associated plasma protein; ROS, reactive oxygen species; SCD40L, soluble CD40 ligand.

border zone; and phase 4 consists of remodeling and repair and begins at 2-3 weeks, persisting for up to a year [1]. Although a number of immune mediators, including cytokines, autoantibodies to myosin and tropomyosin, as well as interferon (IFN)- $\gamma$ have been closely studied, clinically useful circulating inflammatory biomarkers to assist in the diagnosis and prognosis of AMI have yet to be established [2].

Where an infective agent is responsible for myocardial damage, acute viral myocarditis being the prototype, once again clinically helpful inflammatory biomarkers are not available. Temporally, three phases exist when myocardial damage is due to infection: 1) myocyte destruction by the virus; 2) an innate immune response, which ultimately may cause more harm than good; and 3) possible myocardial damage, resulting in a dilated cardiomyopathy, and where once again, autoantibodies may play a role $[3,4]$.

What often is overlooked is the role of inflammation in the progression of coronary artery disease (CAD), 


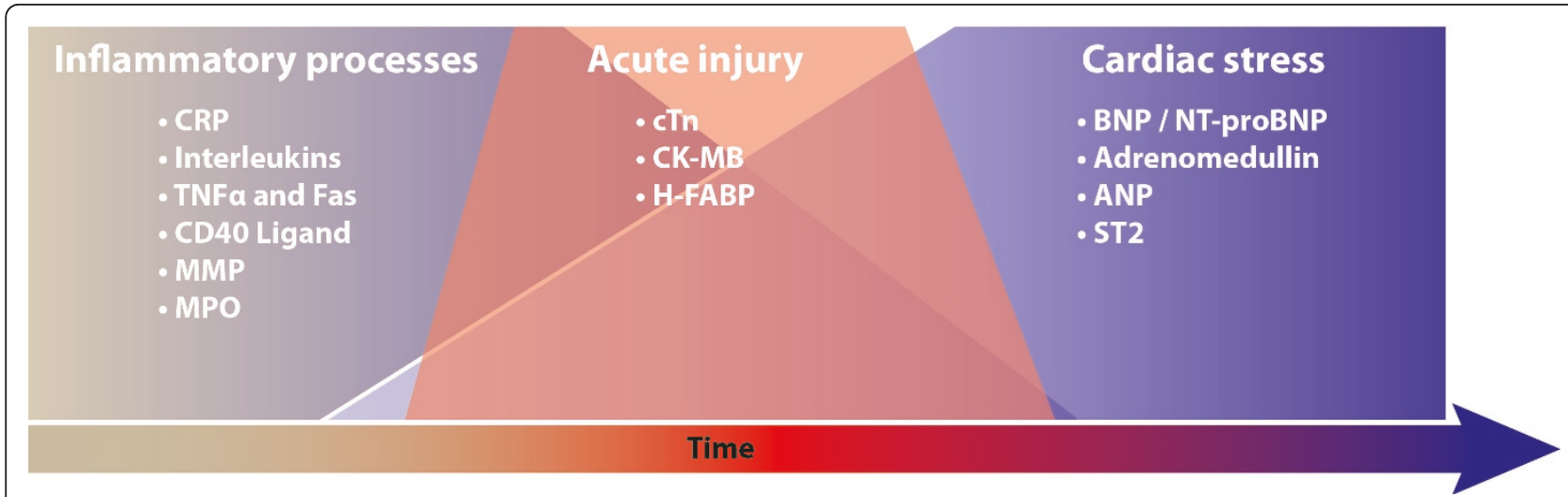

Figure 2 Evolution of cardiac dysfunction and the associated changes in cardiac biomarkers. (see legend to Figure 1 for abbreviations).

even in the absence of myocardial necrosis, and here the role of inflammatory markers hold more promise [5]. Unfortunately in the critical care setting, where organs other than the heart are usually compromised, the specificity of these markers, including tumor necrosis factor (TNF)- $\alpha, \mathrm{CD}-40 \mathrm{~L}$, interleukins (IL-18, IL-6, IL-33, and IL-1a), CRP, fibrinogen, pentraxin 3, and matrix metalloproteinases, are markedly compromised. The potential of inflammatory markers is promising however, and even in apparently nonimmune settings, such as emotional stress-induced acute onset cardiomyopathy, inflammatory pathways appear to play a pivotal part [6]

\section{Biomarkers of myocardial injury Cardiac troponins (cTn)}

The evolving story of cTn to diagnose acute myocardial damage is as fascinating as it is beguiling. The troponin era began with the development of a double antibody, two-step enzyme immunoassay for TnT in 1989 [7]. Evolution of these developments now has cTn as the central component of the definition of an AMI [8]. The superior diagnostic power of cTn is demonstrated by correlation with histological findings [9]. A diagnosis of AMI is predicted on the detection of an increase or decrease of cTn, with at least one value $>99 \%$ percentile upper reference limit (URL) in patients with evidence of myocardial ischemia. This evolution extended the role of Tn from being a marker only for AMI to that of acute coronary syndrome (ACS) and secondary myocardial damage from conditions, such as pulmonary embolus (PE), cardiac trauma, and chemotherapy-induced myocardial damage. The latest step in the evolution is the development and rapid uptake of the hs-cTn assays around the world.

\section{Comparison of $\mathrm{cTnT}$ and $\mathrm{cTnl}$}

The cTn complex, consisting of three proteins $(\mathrm{C}, \mathrm{I}$, and $\mathrm{T}$ ) encoded by different genes, plays a pivotal role in the modulation of calcium-dependant sarcomere contraction
$[10,11]$. cTnI and cTnT have cardio-specific isoforms not found in skeletal muscle, making for highly specific markers of myocardial damage. Both cTnI and cTnT are released from necrotic myocardium, ischemic and nonischemic-induced, as intact proteins and degradation products [12]. Although experimental data indicates that cTn only leaks out of the cell after cell death, the finding of cTn in marathon runners and after inducible myocardial ischemia, raises the possibility of it occurring in the absence of necrosis $[13,14]$. The cTnT assay is only available from one manufacturer, whereas cTnI assays are available from a number of vendors, rendering interpretation confusing because of the lack of standardization. It is important that the clinician has an understanding of the assay used in their institution, including analytical quality and limitations. Increasing sophistication of the assays has resulted in fewer falsenegatives and false-positives; however, the presence of cTn autoantibodies in the blood or marked hemolysis can produce inaccurate results $[15,16]$.

\section{cTn as a diagnostic marker}

The central consideration in the interpretation of an elevated serum cTn is that it is a marker of myocardial damage, but on its own it does not determine the etiology of the damage. cTnT and cTnI demonstrate similar diagnostic ability in detection of myocardial damage despite analytical differences [17]. The criteria for diagnosing an AMI are a rising or falling pattern of blood cTn levels in association with clinical features of myocardial ischemia. An international taskforce comprising of the American Heart Association/World Health Foundation/European Society of Cardiology/American College of Cardiology Foundation (AHA/WHF/ESC/ACCF) recommends a cutoff value set at $99^{\text {th }}$ percentile of URL, or the concentration at which the assay achieves a coefficient of variation of $10 \%$ if that exceeds the $99^{\text {th }}$ percentile $[8,18]$. Clinical features of AMI include classical symptoms, ECG changes, regional wall motion 


\begin{tabular}{l} 
Table 1 Conditions commonly associated with cTn \\
elevations \\
\hline Arrhythmias* \\
Aortic dissection* \\
Acute heart failure* \\
Coronary vasospasm* \\
Cardiomyopathy, e.g., postpartum \\
Coronary vasculitis, e.g., SLE, Kawasaki Syndrome* \\
Cardiac contusion \\
Chemotherapy \\
Hypertension* \\
Myocarditis \\
Pulmonary embolus \\
Sepsis/septic shock \\
SIRS \\
Takotsubo cardiomyopathy \\
Renal failure \\
Severe neurological disorders \\
Pulmonary hypertension - severe \\
Radiofrequency ablation* \\
Pericarditis \\
Extreme exertion
\end{tabular}

*Elevations of cTn in the absence of overt ischemic heart disease or in the patient with normal coronary arteries include those patients with myocardial ischemia from noncoronary disease, and by definition come into the Ml type II classification. Certain conditions result in chronic elevations of cTn, including chronic renal failure, chronic heart failure, stable CAD, marked left ventricular wall hypertrophy, and aortic stenosis [11].

abnormalities, or imaging evidence of new loss of viable myocardium. In the absence of these features, an alternative cause of the cTn elevation and myocardial damage should be sought (Table 1).

The timing of cTn elevations becomes increasingly important with the development of more sensitive assays and an understanding of the manner in which cTn is released from the damaged myocyte is helpful. An acute process involves a rise and fall with an increase occurring 2-4 hours after symptoms and remaining elevated for 7-14 days. Therefore, serial measurements, usually 36 hours apart are recommended [19]. The less sensitive cTn assays require significant elevations, whereas the newer hs-cTn assay requires smaller ones. Biological variation may become more important at these lower levels bringing other challenges to interpreting the result [20]. If the initial cTn level is not elevated, then serial measurements over 6-9 hours are necessary. If this second sample is still not elevated but clinical suspicion of an MI remains high, then a further sample at 12-24 hours should be considered. An earlier resampling at 3 hours still provides approximately $80 \%$ sensitivity in detecting AMI [21]. Age seems to be a confounding factor. A study that included 1,098 patients who underwent a single hs-cTn sample on presentation to the emergency department with symptoms suggestive of an AMI identified the best cutoff value, separating AMIs from non-AMIs, to be much higher. The hs-cTnT value for patients older than aged 70 years at $54 \mathrm{ng} / \mathrm{l}$ was nearly four times the $99^{\text {th }}$ percentile, although close to the $99^{\text {th }}$ percentile for two different hs-cTnI assays [22].

The introduction of hs-cTn, with precision sensitivity improved from the $\mu \mathrm{g} / \mathrm{l}$ to the $\mathrm{ng} / \mathrm{l}$ range, has enhanced the sensitivity and reduced the time to diagnose AMI in the acute setting. The use of a single hscTnI measurement at 3 hours in patients presenting with chest pain, using a cutoff of $40 \mathrm{ng} / \mathrm{l}$, gave a negative predictive value (NPV) of $84.1 \%$ and positive predictive value (PPV) of $86.7 \%$; these findings predicted a $30 \%$ increase in cTn levels at 6 hours [23]. The diagnostic accuracy of a number of different hs-cTn assays were found to be excellent and much superior to the standard assays [24]. Interpretation is reliant upon the baseline level, the increase at a selected time interval (usually 6 hours), and the clinical setting. For example, whereas hs-cTnT assay has a cutoff value of $14 \mathrm{ng} / \mathrm{l}$, a second sample at 6 hours is recommended when the value is between 14-100 $\mathrm{ng} / \mathrm{l}$ to improve the specificity and PPV of the assay. A single reading above $100 \mathrm{ng} / \mathrm{l}$ is considered a high risk for ACS and warrants management accordingly. When testing for the optimal change of cTnI, Apple found a $\geq 30 \%$ increase from baseline (admission) level in the 4-10 hours follow-up measurements provided a sensitivity of $71 \%$ and specificity of 91\% [25]. Giannitsis and associates demonstrated that, compared with the $4^{\text {th }}$ generation cTnT, the admission hs-cTnT assay (at a cutoff of $99^{\text {th }}$ percentile) detected more evolving non-STEMI cases $(61.5 \%$ vs. $7.7 \%)$. The detection by hs-cTnT further improved to $100 \%$ within 6 hours. The overall diagnosis of MI increased by $34.6 \%$ [26]. A doubling of the hs-cTnT concentration within 3 hours in the presence of a second concentration $\geq 99^{\text {th }}$ percentile is associated with a PPV of $100 \%$ and NPV of $88 \%$ [26]. Such an approach, or a variant of it, is suitable for the development of protocols in the emergency department but unfortunately less so in the ICU where confounding issues are present.

The sedated hemodynamically unstable patient on positive pressure ventilation does not usually provide the classical symptoms of myocardial ischemia. ECG changes, often on a background of an already abnormal ECG, are nonspecific, and confounding factors, such as renal failure or heart failure, are present. Many conditions commonly found in an ICU are associated with elevated cTn levels, even in the absence of definite coronary artery pathology leading to myocardial ischemia (Table 1). Added to this is the likelihood that many MI will be a type II class as described in the international consensus guidelines (Table 2). 


\begin{tabular}{|c|c|}
\hline $\begin{array}{l}\text { Types of myocardial } \\
\text { infarction }\end{array}$ & Clinical classification \\
\hline Type 1 & Spontaneous myocardial infarction related to ischemia due to primary coronary event. \\
\hline Type 2 & $\begin{array}{l}\text { Myocardial infarction secondary to ischemia due to increased oxygen demand or decreased supply, e.g., coronary artery } \\
\text { spasm, coronary embolism, anemia, arrhythmias, hypertension, or hypotension. }\end{array}$ \\
\hline Type 3 & $\begin{array}{l}\text { Sudden, unexpected cardiac death with symptoms and signs of cardiac ischemia. Death occurs before blood cardiac } \\
\text { biomarkers able to be measured. }\end{array}$ \\
\hline Type 4a & $\begin{array}{l}\text { Myocardial infarction associated with percutaneous } \\
\text { Intervention. }\end{array}$ \\
\hline Type 4b & Myocardial infarction associated with stent thrombosis as documented by angiography or at autopsy. \\
\hline Type 5 & Myocardial infarction associated with coronary artery bypass surgery. \\
\hline
\end{tabular}

Abridge version based on Reference [8]

The advent of hs-cTn brings a definite improvement in diagnostic accuracy but at the expense of lower specificity, a challenge already encountered on a daily basis in the ICU with standard assays. However, this development should be seen as a positive step with the higher diagnostic accuracy, but further studies in the critically ill population are required to better define its use in this population.

\section{Cardiac troponin as a prognostic marker}

Elevated cTn is associated with poor prognosis in patients with acute ischemia $[27,28]$. cTnI and cTnT have comparable prognostic performance, except for patients with chronic renal failure where cTnT but not cTnI was a predictor of a worse outcome [29]. It is noteworthy that the prognostic value of cTn is not limited to ischemic heart disease. In a systematic review of an elevated cTn in critically ill patients, looking at 23 studies involving 4,492 patients, Lim and colleagues found a 2.5 times increased risk of death and an increased length of ICU stay of 3 days and hospital stay of 2.2 days [30].

\section{Creatine kinase-MB}

When first described in 1972, the electrophoresis methods required for separation of the cardiac isoenzymes had low analytical specificity [31]. An immunoinhibition method resulted in a useful clinical test and creatine kinase-MB (CK-MB), in combination with aspartate transaminase and lactate dehydrogenase, became the triad of biomarkers used for the diagnosis of AMI. CK$\mathrm{MB}$, is released within 2-4 hours, peaks at 24 hours following pressure overload or ischemia, and returns to normal by 36-72 hours [32]. It is a sensitive marker of MI, but a single measurement on presentation has low sensitivity. Lack of specificity is a problem; $10 \%$ of patients experience chest pain with an elevated CK-MB but normal cTn [33]. It is present in small amounts in skeletal muscle (1-3\% of total CK), and a large muscle injury can be compounded by the re-expression of proteins producing the CK-MB isoenzyme [34]. The advent of cTn has relegated CK-MB, previously the favorite cardiac biomarker of myocardial necrosis, into the background and its role in the critically ill patient has been superseded.

\section{Fatty acid binding proteins (FABPs)}

Fatty acid binding proteins (FABPs)-small proteins located in the cytoplasm-facilitate transport of fatty acids and other lipids within the cell. Heart-type FABP (H-FABP) is a sensitive marker of myocyte damage and, unlike troponin, is released by both ischemia and necrosis. It also is released more rapidly than troponin, although the advent of hs-cTn will overcome the advantage of FABP in this regard. H-FABP is released from the damaged cell within 1-3 hours, returning to normal by 12-24 hours. It is now available as a point of care test for the diagnosis of AMI in many countries and also has good data to support its use in prognostication from MI $[35,36]$. The diagnostic sensitivity of H-FABP for cardiac injury is $93.1 \%$, higher than CK-MB and cTn [37]. There is a dearth of information about the use of $\mathrm{H}$-FABP for the diagnosis of MI in the critically ill population; however, there may be a role in the risk stratification of pulmonary embolism (PE) in critically ill patients.

\section{Biomarkers of cardiac stress}

\section{Natriuretic peptides (NP)}

Primarily for maintaining osmotic and cardiovascular homeostasis, the NP family includes multiple peptides and receptors. Present throughout all vertebrate classes, including fish, amphibians, mammals, and birds, this family of related peptides and specific receptors is an integral system in the control of hydromineral balance and blood pressure [38]. In mammals, the NPs include atrial natriuretic peptide (ANP), brain or B-type natriuretic peptide (BNP), C-type natriuretic peptide (CNP), dendroaspis natriuretic peptide (DNP), and urodilatin. They share similar structures, with ANP, BNP, and CNP having a ring of 17 amino acids, 11 of which are identical. Urodilatin and ANP having an identical 
ring [39]. The activities of NPs and endothelins (ET) are closely associated, with ANP and BNP inhibiting ET-1 release and ET-1 stimulating NP synthesis [39].

Although the earliest investigations into the application of NP in everyday medicine involved ANP, with more recent investigations on CNP, DNP, and urodilatin, BNP and NT-proBNP is where most effort has been directed. The pre-prohormone BNP is a 134 aminoacid peptide synthesized in ventricular myocytes, with subsequent cleaving into the 108 aminoacid prohormone BNP, which is released into the circulation during hemodynamic stress [40]. Corin, a circulating endoprotease, cleaves the prohormone BNP into the biologically active BNP (32 amino acids) and inactive NT-proBNP (76 amino acids). BNP, having a half-life of 20 minutes, is cleared by cells containing BNP receptors, whereas NT-proBNP, which is cleared by the kidney, has a longer half-life (60-120 minutes); this explains the higher circulating concentrations compared with BNP.

The obvious clinical applications of BNP and NT BNP have led to the development of fully automated assays for both; some understanding by the clinician of the specific assay used is important, because some immunoassays cannot differentiate between active and inactive forms. For example, some assays actually measure a mixture of both BNP and NT-proBNP, whereas various breakdown products of BNP may be included in the assay [41].

Clinical application of BNP/NT-proBNP The clearest clinical benefit of the application of BNP and NT-
proBNP has been the diagnosis and prognosis of heart failure. Regular application in the emergency department is based on studies such as Breathing Not Properly, where a serum BNP level > $100 \mathrm{pg} / \mathrm{ml}$ was demonstrated to diagnose congestive heart failure (CHF) with a sensitivity of $90 \%$ and specificity $73 \%[42,43]$. Similar diagnostic accuracy was identified with NT-proBNP, with a level of $500 \mathrm{ng} / \mathrm{ml}$ used by most investigators $[44,45]$. BNP levels can be elevated in patients with CAD, leading to search for a diagnostic and prognostic role in this group $[46,47]$.

Only a weak correlation between pulmonary capillary wedge pressure and serum BNP level in the ICU patient has been found [48]. In a review on the role of BNP and NT-proBNP in the management of heart failure, Omland cautions the interpretation of elevated levels in the ICU setting [49]. Our group, along with others, demonstrated that there may be a role in discriminating those patients with from those without cardiac dysfunction in the ICU [50-52]. However, the actual type of cardiac dysfunction is not clarified by the finding of an elevated BNP. Age and gender also must be taken into account in the interpretation of elevated serum levels [53].

The challenge is in translating the value of BNP in the diagnosis of HF in the emergency department, or prognostic value of $\mathrm{CHF}$ in the outpatient setting, to a role in the critically ill patient. Usually multiple comorbidities, particularly renal failure or sepsis, can cause elevation of serum levels in the absence of heart failure. Numerous factors may contribute to the measurement BNP level in the serum in a single patient (Figure 3 ).

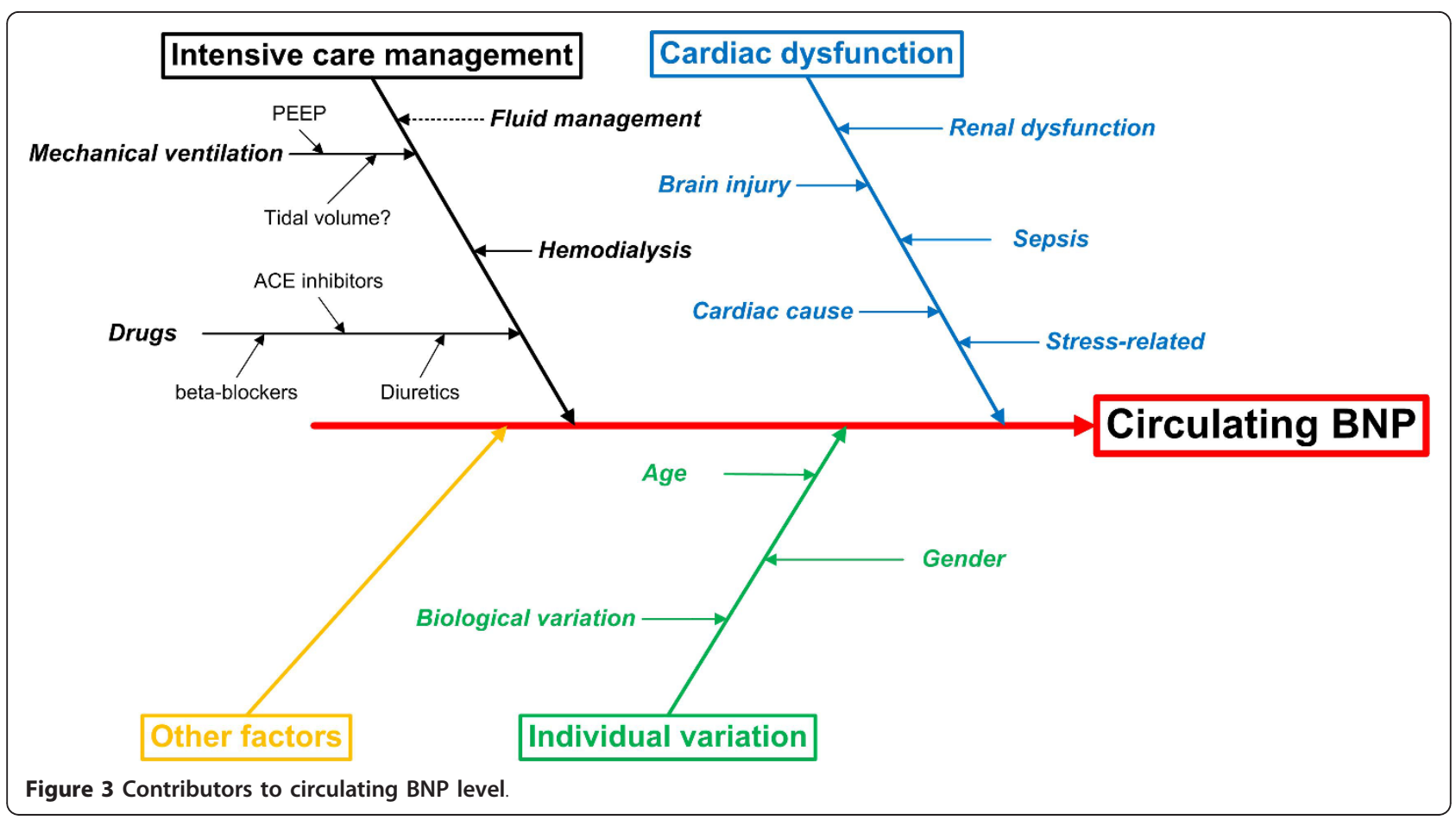


Does a prognosis role exist for the natriuretic peptides? Numerous studies have sought to clarify a role for NPs as prognostic markers in the ICU setting, yet the results have been conflicting and insufficiently robust to modify a patient's management [54-58]. Although an elevated NP most likely represents cardiac dysfunction even in the critically ill patient, they lack discriminating power to identify what type of cardiac dysfunction is present and cannot be compared with the application of echocardiography, which should be routinely used in critically ill patients with underlying cardiac dysfunction. A in-depth review by Christenson concluded the utilization of BNP or NT-BNP did not have a substantive role in the management of critically ill patients in the ICU [59].

\section{Adrenomedullin (ADM)}

A peptide of 52 amino acids, ADM is synthesized and found in heart, adrenal medulla, lungs, and kidneys. In the heart, it is produced in response to volume and pressure overload and has similar actions to the NPs [60]. It is a potent vasodilator, inducing diuresis and natriuresis. Plasma ADM levels are significantly elevated in heart failure and AMI, correlated with severity of illness, and have some prognostication for mortality in AMI [61]. It is insufficiently characterized, especially in regard to measurements and clear guidance as to what elevation is important in the ICU setting.

\section{Usefulness of cardiac biomarkers in noncoronary artery pathologies commonly presenting the in ICU Acute pulmonary embolus}

$\mathrm{CB}$ can have roles in both the diagnosis and prognosis of a patient with PE. Elevation of cTn results from increased metabolic demand and reduced myocardial perfusion, which causes right ventricular ischemia/ microinfarction, whereas increased wall stress results in elevation of BNP. Kucher and Goldhaber in 2003 concluded that a cTn below the cutoff required for that required to diagnose $\mathrm{AMI}$, or a $\mathrm{BNP}<50 \mathrm{ng} / \mathrm{ml}$, have a $>98 \%$ negative predictive value for in hospital death by PE [62]. La Vecchia and associates demonstrated that a cTnI $>0.06 \mu \mathrm{g} / \mathrm{L}$ was associated with a subsequent mortality of $36 \%$ compared with those $<0.06 \mu \mathrm{g} / \mathrm{L}$, and the former had a greater need for inotropes and mechanical ventilation [63]. The role of NP is less certain, and although some investigators regard NT-proBNP as a better prognosticator than currently used clinical scores in PE, any additional value over cTn or H-FABP in acute PE is not proven [64].

The role of $C B$ in risk stratification is firmly established, and $\mathrm{CB}$ are included as principal markers in the European Society of Cardiology guidelines on the diagnosis and management of acute pulmonary embolus [65]. The presence of elevated cTn and/or BNP places the patient outside the low risk category $(<1 \%$ mortality), and when combined with echo features of cardiac dysfunction and hypotension place the patient in the high-risk ( > 15\% mortality) category. The combination of specific CB and echocardiographic abnormalities has important management ramifications in regards to consideration of thrombolytic therapy for acute PE, even in the hemodynamically stable patient $[62,66]$.

$\mathrm{H}-\mathrm{FABP}$ seems to have better diagnostic accuracy and better prognostic value compared with cTn and BNP in cases of PE. Puls and associates in a study of 107 patients found that normal H-FABP on admission predicts an absence of significant complications or death. The PPV for H-FABP was $41 \%$ compared with $29 \%$ for cTn and $19 \%$ for proBNP [67]. In a more recent study involving 101 consecutive patients with confirmed PE and echocardiographic signs of right ventricular overload, but without hypotension or shock, none of the patients with normal H-FABP $(\mathrm{N}=$ 87) on admission to the emergency department experienced clinical deterioration, required inotropic support, or died. In the H-FABP-positive group $(n=14)$, the degree of RV dysfunction was greater, ten had clinical deterioration that required inotropic support, and eight died [68].

\section{Sepsis}

It has been recognized for more than a decade that elevated cTn in septic patients is associated with a higher mortality [69]. cTn is elevated in $12-85 \%$ of ICU patients with sepsis of severe inflammatory syndrome, with a meta-analysis including 3,278 patients from 20 studies, giving a median value of $43 \%$ [30].

The wide range of prevalence probably relates to the heterogeneity found in septic studies but clearly an elevated $\mathrm{cTn}$ is not uncommon. The real uncertainty comes from the cause of the troponin release, whether it is global myocardial ischemia (i.e., type II AMI), the myocytoxic effects of cytokines, reactive oxygen species or endotoxins, or exacerbation of chronic coronary artery small vessel disease [70]. cTnI also was elevated in septic patients who display evidence of isolated and reversible diastolic dysfunction [71]. Adding to the uncertainty is whether any such myocyte damage is persistent, with autopsy studies not necessarily revealing irreversible damage in shocked patients with premortem elevated cTns [72].

In a study of 207 patients with severe sepsis and septic shock, circulating cTnT was detected in $60 \%$ of the patients using the fourth-generation cTnT assays and $100 \%$ by the hs-cTnT assay [73]. The levels of hs-cTnT were associated with disease severity and survival, although it was not an independent predictor of in-hospital mortality. The authors proposed a potential role for hs-cTn in sepsis as an early marker of shock. Although NP levels are elevated in sepsis, there is 
controversy about whether they add to diagnostic or outcome information $[54,74]$.

\section{Acute heart failure: non-CAD}

$\mathrm{cTn}$ is elevated in patients with HF even in the absence of CAD [75,76]. Lacking diagnostic sensitivity and specificity for the diagnosis of heart failure, it is associated with increased risks of mortality and cardiac morbidity [77-79]. For example, elevated cTnI predicts mortality in patients hospitalized for congestive heart failure [75].

\section{Renal failure}

Because baseline serum cTn levels are already elevated in chronic renal failure (CRF), the diagnosis of a $\mathrm{MI}$ is based on $>20 \%$ increase in levels at 6-9 hours after presentation [80]. This recommendation by the National Academy of Clinical Biochemistry Laboratory is based on the "older" cTn assays, and the situation has become more challenging with a recent study that demonstrated that in a cohort of asymptomatic patients with endstage renal disease, $100 \%$ had a hs-cTn level $>99 \%$ percentile value [81]. In a comparison of the prognostic value of cTn and BNP/NT-proBNP in 143 CRF patients on dialysis, Hickman and associates demonstrated that NT-proBNP was superior to cTn [82].

\section{Acute lung injury and weaning}

Although classically a "cardiac biomarker," BNP has perhaps best found a role in the ICU in the diagnosis of hypoxic respiratory failure and determining the optimal timing for extubation. Rana and colleagues found that a BNP level $<250 \mathrm{pg} / \mathrm{ml}$ supports the diagnosis of acute lung injury $(\mathrm{AUC}=0.71)$, with improved accuracy when patients with renal failure were excluded $(\mathrm{AUC}=0.82)$ [83]. Other studies use varying cutoff serum BNP levels and have different diagnostic accuracy reducing the clinical usefulness of a single sample [84].

A recent study of 100 patients, who underwent a 48hour spontaneous breathing trial before extubation, underwent echocardiographic evaluation and NP sampling immediately before the trial commenced and at the end, before extubation. A baseline cutoff BNP level of $263 \mathrm{ng} / \mathrm{l}$ and $1,343 \mathrm{ng} / \mathrm{l}$ for NT-proBNP before the trial, or an increase of 48 and $21 \mathrm{ng} / \mathrm{l}$ respectively for BNP and NT-proBNP, accurately predicted those patients who failed extubation as a result of underlying cardiac failure. BNP performed better than NT-proBNP [85]. A prior study recruited patients who received mechanical ventilation for $>24$ hours demonstrated that baseline BNP was higher in patients with subsequent weaning failure and correlated to weaning duration [86].

\section{Multimarker diagnosis of cardiac dysfunction}

The use of multiple biomarkers has the theoretical attraction of improving both sensitivity and specificity in the diagnosis of different cardiac disorders, with particular relevance in the ICU where multiple confounding factors exist. The combination of cTnT, ECG, and ischaemia-modified albumin identified ischemia in $95 \%$ of patients presenting with chest pain [87]. However, other studies do not support the benefit of multimarkers compared with a single one in the emergency department or ICU $[88,89]$.

In predicting 6-month mortality from acute heart failure, Nunez and associates demonstrated the combination of CA-125 and BNP added prognostic value to that provided by BNP alone [90].

\section{Potentially future cardiac biomarkers}

MicroRNAs (also known as miRs or miRNAs) are approximately 20-25 nucleotide long noncoding ribonucleic acids (RNAs) that negatively regulate or inhibit gene expression by binding to sites in the 3' untranslated region of targeted messenger RNAs [91-94]. They have been found to be involved in almost every biological process, from cellular differentiation and proliferation to cell death and apoptosis. Many different types of miRNAs can be detected in circulating blood, and these miRNAs are present in a remarkably stable form that even withstand repetitive freezing/thawing cycles and are protected against RNases. Of the thousands of miRNAs described to date in humans, many exhibit tissuespecific patterns of expression can be detected in circulating blood. Ones that regulate the cardiovascular system have been identified [95-97]. They can be divided into four groups:

1. miRNAs regulating endothelial function and angiogenesis: miR126, miR17-92 cluster (miR17, miR20a, miR92a), miR130a, miR221, miR21

2. Cardiac myocyte-specific mRNA: miR208a

3. Cardiac myocyte (highly expressed) and skeletal muscle miRNAs: miR1, miR 133a, miR499.

Smooth muscle miRNAs: miR143, miR145

Since the half-life of circulating miRNA is counted in hours and their breakdown do not seem to be compromised by the presence of organ dysfunction, they hold promise as very specific, accurate markers of cardiac dysfunction in the critically ill patient.

\section{Conclusions}

Measuring plasma $\mathrm{CB}$ is often a routine undertaking for most critical care physicians, and the increasingly accurate markers developed over the years have an important place in everyday practice. The obvious advantages experienced in the emergency department or cardiology ward are not always shared in the ICU where cofounders frequently make for a more cautious interpretation and careful consideration of subsequent management decisions. Yet, an understanding of the underlying strengths and weaknesses now available from a 
considerable research and clinical database should lead to an appreciation of their immense value.

\section{Authors' contributions}

ASM and SJH both drafted manuscript. Both authors read and approved the final manuscript.

\section{Competing interests}

The authors declare that they have no competing interests.

Received: 7 December 2011 Accepted: 7 March 2012

Published: 7 March 2012

\section{References}

1. Blankesteijn W, Cremmers E, Lutgens E, Cleutjens J, Daemen M, Smits J: Dynamics of cardiac wound healing following myocardial infarction: observations in genetically altered mice. Acta Physiol Scand 2001, 173:75-82.

2. Liao Y-H, Cheng X: Autoimmunity in myocardial infarction. Int I Cardio 2006, 112:21-26

3. Caforio A: Ciculating cardiac autoantibodies in dilated cardiomyopathy and myocarditis: pathogenetic and clinical significance. Eur I Heart Failure 2002, 4(4):411-417.

4. Cooper $L$ : The heat is off: immunosuprression for myocarditis revisited. Eur Heart J 2009, 30:1936-1939.

5. Packard R, Libby P: Inflammation in atherosclerosis: from vascular biology to biomarker discover and risk prediction. Clin Chem 2008, 54:24-38.

6. Wittstein I, Thiemann D, Lima J, Baughman K, Schulman S, Gerstenblith G, Wu K, Rade J, Bivalacqua T, Champion: Neurohumoral features of myocardial stunning due to sudden emotional stress. N Engl J Med 2005, 352:539-548.

7. Dolci A, Panteghini M: The exciting story of cardiac biomarkers: from retrospective detection to gold diagnostic standard for acute myocardial infarction and more. Clin Chimica Acta 2006, 369:179-187.

8. Thygesen $\mathrm{K}$, Alpert J, White H: Joint ESC/ACCF/AHA/WHF Task Force for the Redefinition of Myocardial Infarction. Universal definition of myocardial infarction. Eur Heart J 2007, 28:2525-2538.

9. Ooi D, Isotalo $P$, Veinot J: Correlation of antemortem serum creatine kinase, creatine kinase-MB, troponin I and troponin $\mathrm{T}$ with cardiac pathology. Clin Chem 2000, 46:338-344.

10. Parmacek M, Solaro R: Biology of troponin complex in cardiac myocytes Prog Cardiovasc Dis 2004, 47:159-176.

11. Thygesen K, Mair J, Katus H, Plebani M, Venge P, Collinson P, Lindahl B, Giannitsis E, Hasin Y, Galvani M, Tubaro M, Alpert J, Biasucci L, Koenig W, Mueller C, Huber K, Hamm C, Jaffe A: Recommendations for the use of cardiac troponins measurements in acute cardiac care. Eur Heart J 2010 31:2197-2206

12. Hessel M, Michielsen E, Atsma D, Schalij M, van der Valk E, Bax W, Hermens W, van Dieijen-Visser MP, van der Laarse A: Release kinetics of intact and degraded troponin I and T after irreversible cell damage. Exp Mol Pathol 2008, 85:90-95.

13. Fishbein M, Wang T, Matijasevic M, Hong L, Apple F: Myocardial tissue troponins $T$ and I. An immunohistochemical study in experimental models of myocardial ischemia. Cardiovasc Pathol 2003, 12:65-71.

14. Regwan S, Hulten E, Martinho S, Slim J, Villines T, Mitchell J, Ahmad S: Marathon running as a cause of troponin elevation: a systematic review and meta-analysis. J Interv Cardiol 2010, 23:443-450.

15. Zhu Y, Jenkins M, Brass D, Ravago P, Horne B, Dean S, Drayton N Heterophilic antibody interference in an ultra-sensitive 3-site sandwich troponin I immunoassay. Clin Chim Acta 2008, 395:181-182.

16. Panteghini M: Assay-related issues in the measurement of cardiac troponins. Clin Chem Acta 2009, 402:88-93.

17. Panteghini M: Acute myocardial syndrome. Biochemical strategies in the troponin era. Chest 2002, 122:1428-1435.

18. European Heart Journal: Universal definition of myocardial infarction. Eur Heart J 2007, 28:2525-2538

19. Wu A, Jaffe A: The clinical need for high-sensitivity troponin assays for acute coronary syndromes and the role of serial testing. Am Heart $J$ $2008,155: 208-214$
20. Wu A, Lu Q, Todd J, Moecks J, Wians F: Short- and long-term biological variation in cardiac troponin I measured with a high-sensitivity assay: implications for clinical practice. Clin Chem 2009, 55:52-58.

21. McRae A, Kavsak P, Lustig V, Bhargava R, Vandersluis R, Palomaki G, Yerna $M$, Jaffe A: Assessing the requirement for the 6 hour interval between specimans in the Americal Heat Association classification of myocardial infraction in epidemiology and clinical research. Clin Chem 2006, 52:816-818

22. Reiter $M$, Twerenbold R, Reichlin T, Haaf $P$, Peter P, Meissner J, Hochholzer W, Stelzig C, Freese M, Heinisch C, Breidthardt T, Freidank H, Winkler K, Campodarve I, Gea J, Mueller C: Early diagnosis of acute myocardial infarction in the elderly using more sensitive cardiac troponin assays. Eur Heart J 2011, 32:1379-1389

23. Keller T, Zeller T, Peetz D, Tzikas S, Roth A, Czyz E, Bickel C, Baldus S, Warnholtz A, Fröhlich M, Sinning S, Eleftheriadis M, Wild P, Schnabel R, Lubos E, Jachmann N, Genth-Zotz S, Post F, Nicaud V, Tiret L, Lackner K, Münzel T, Blankenberg S: Sensitive troponin I assay in early diagnosis of acute myocardial infarction. N Engl J Med 2009, 361:868-877.

24. Reichlin T, Hochholzer W, Bassetti S, Steuer S, Stelzig C, Hartwiger S, Biedert S, Schaub N, Buerge C: Early diagnosis of myocardial infraction with sensitive cardiac troponin assays. N Engl J Med 2009, 361:858-867.

25. Apple F, Pearce L, Smith S, Kaczmarek J, Murakami M: Role of monitoring changes in sensitive cardiac troponin I assay results for early diagnosis of acute myocardial infarction and prediction of risk of adverse events. Clin Chem 2009, 55(5):930-937.

26. Giannitsis E, Becker M, Kurz K, Hess G, Zdunek D, Katus H: High-sensitivity cardiac troponin $\mathrm{T}$ for early prediction of evolving non-ST-segment elevation myocardial infarction in patients with suspected acute coronary syndrome and negative troponin results on admission. Clin Chem 2010, 56(4):642-650.

27. Ottani F, Galvani M, Nicolini F, Ferrini D, Pozzati A, Di Pasquale G, Jaffe A: Elevated cardiac troponin levels predict the risk of adverse outcome in patients with acute coronary syndromes. Am Heart J 2000, 140:917-927.

28. Heidenreich P, Alloggiamento T, Melsop K, McDonald K, Go A, Hlatky M: The prognostic value of troponin in patients with non-ST elevation acute coronary syndromes: a meta-analysis. J Am Coll Cardiol 2001, 38:478-485.

29. Khan N, Hemmelgam B, Tonelli M, Thompson C, Levin A: Prognostic value of troponin $\mathrm{T}$ and I among asymptomatic patients with end-stage renal disease a meta-analysis. Circulation 2005, 112:3088-3096.

30. Lim W, Qushmaq I, Devereaux P. Heels-Ansdell D, Lauzier F, Ismaila A, Crother M: Elevated cardiac troponin measurement in critically ill patients. Arch Int Med 2006, 166:2446-2454.

31. Roe C, Limbird L, Wagner G, Nerenberg S: Combined isoenzyme analysis in the diagnosis of myocardial injury: application of electrophoretic methods for the detection and quantitation of the creatine phosphokinase MB isoenzyme. J Lab Clin Med 1972, 80:577-590.

32. Sobel B, Shell W: Serum enzyme determination in the diagnosis and assessment of myocardial infarction. Circulation 1972, 45:71-482

33. Lin J, Apple F, Murakami M, Luepker R: Rates of positive cardiac troponin I and creatine kinase MB mass among patients hospitalized for suspected acute coronary syndromes. Clin Chem 2004, 50:333-338.

34. Wolf P: Abnormalities in serum enzymes in skeletal muscle diseases. Am J Clin Pathol 1991, 95:293-196

35. Mad P, Domanovits H, Fazelnia C: Human heart-type fatty acid binding protein as a point of care test in the early diagnosis of acute myocardial infarction. QJM 2007, 100:203-210.

36. O'Donoghue M, de Lemos J, Morrow D: Prognostic utility of heart-type fatty acid binding protein in patients with acute coronary syndromes. Circulation 2006, 114:550-557.

37. Tanaka T, Sohmiya K, Kitaura Y, Takeshita H, Morita H: Clinical evaluation of point of care testing of heart-type fatty acid binding protein (H-FABP) for the diagnosis of acute myocardail infarction. J Immunoassay Immunochem 2006, 27:225-238

38. Toop T, Donald J: Comparative aspects of natriuretic peptides physiology in nonmammalian vertebrates: a review. J Comp Physiol 2007, 174:189-204.

39. Piechota M, Banach M, Jacon A, Rysz J: Natriuretic peptides in cardiovascular diseases. Cell Molec Biol Lett 2008, 13:155-181. 
40. Vanderhayden M, Goethals M, Verstreken S, De Bruyne B, Muller K, Van Schuerbeeck E, Bartunek J: Wall stress modulates brain natriuretic peptide production in pressure overload cardiomyopathy. JACC 2004, 2349-2354.

41. Vanderheyden M, Vrints C, Verstreken S, Bartunek J, Beunk J, Goethals M: Btype natriuretic peptide as a marker of heart failure: new insights from biochemistry and clinical applications. Biomarkers Med 2010, 42:315.

42. Maisel A, Mccord J, Nowak R, Hollander J, Wu A: Bedside B-type natriuretic peptide in the emergency diagnosis of heart failure with reduced or preserved ejection fraction. Results from the Breathing Not Properly Multinational Study. J Am Coll Cardiol 2003, 41:2010-2017.

43. Maisel A, Krishnaswarmy P, Nowak R, McCord J, Hollander J, Duc P, Omland T, Storrow A, Abraham W, Wu A, Clopton P, Steg P, Westheim A, Knudsen C, Perez A, Kazanegra R, Hermann H, McCullough PN: Rapid measurement of B-type natriuretic peptide in the emergency diagnosis of heart failure. N Engl J Med 2002, 347:161-167.

44. Coquet I, Darmon M, Doise J, Degres M, Blettery B, Schlemmer B, Gambert P, Quenot J: Performance of N-terminal-pro-B-type natriuretic peptide in critically ill patients:a prospective observational cohort study. Crit Care 2008, 12:R137.

45. Januzzi JJ, Camargo C, Anwaruddin S, Baggish A, Chen A, Krauser D, Tung R, Cameron R, Nagurney J, Chae C, Lloyd-Jones D, Brown D, ForanMelanson S, Sluss P, Lee-Lewandrowski E, Lewandrowski K: The N-terminal ProBNP Investigation of Dyspnoea in the Emergency Department (PRIDE) study. Am J Cardiol 2005, 95:948-954.

46. Jaffe A, Babuin L, Apples F: Biomarkers in acute cardiac disease: the present and the future. J Am Coll Cardiol 2006, 48:1-11.

47. Oremus M, Raina P, Santaguida P, Balion C, McQueen M: A systematic review of BNP as a predictor of prognosis in persons with coronary artery disease. Clin Biochem 2008, 41:260-265.

48. Forfia P, Watkins S, Rame J, Stewart K, Shapiro P: Relationship between Btype natriuretic peptides and pulmonary capillary wedge pressure in the intensive care unit. JACC 2005, 45:1667-1671.

49. Omland TC: Advances in congestive heart failure management in the intensive care unit: B-type natriuretic peptides in evaluation of acute heart heart failure. Crit Care Med 2008, 36(Suppl):S17-S27.

50. Mclean A, Tang B, Nalos M, Huang S, Stewart D: Increased B-type natriuretic peptide is a strong predictor for cardiac dysfunction in intensive care patients. An Int Care 2003, 31:21-27.

51. Abroug F, Ouanes-Besbes L, Nciri N, Sellami N, Addad F, Hamda K: Association of left-heart dysfunction with severe exacerbation of chronic obstructive pulmonary disease: diagnostic performance of cardiac biomarkers. Am J Respir Crit Care Med 2006, 174:990.

52. Kampaliotis D, Kirtane A, Ruisi C, Polonsky T, Malhotra A, Talmor D: Diagnostic and prognostic utility of brain natriuretic peptide in subjects admitted to ICU with hypoxic respiratory failure due to noncardiogenic and cardiogenic pulmonary edema. Chest 2007, 131:964-971.

53. Mclean A, Huang S, Nalos M, Tang B, Stewart D: The confounding effects of age, gender, serum creatinine, and electrolyte concentrations on plasma B-type natriuretic peptides: concentrations in the critically ill. Crit Care Med 2003, 31:2611-2618.

54. McLean A, Huang S, Hyams S, Poh G, Nalos M, Pandit R, Balik M, Tang B, Seppelt I: Prognostic values of B-type natriuretic peptide in severe sepsis and septic shock. Crit Care Med 2007, 35(4):1019-1026.

55. Varpula M, Pulkki K, Karlsson S, Ruokonen E, Pettilä V: FINNSEPSIS Study Group: predictive value of $\mathrm{N}$-terminal pro-brain natriuretic peptide in severe sepsis and septic shock. Crit Care Med 2007, 35:5.

56. Phua J, Koay E, Lee K: Lactate, procalcitonin, and amino-terminal pro-Btype natriuretic peptide versus cytokine measurements and clinical severity scores for prognostication in septic shock. Shock 2008, 29(3):328-333

57. Kandil E, Burack J, Sawas A, Bibawy H, Schwartzman A, Zenilman M, Bluth M: B-type natriuretic peptide: a biomarker for the diagnosis and risk stratification of patients with septic shock. Arch Surg 2008, 143(3):242-246.

58. Cuthbertson B, Patel R, Croal B, Barclay J, Hillis G: B-type natriuretic peptide and the prediction of outcomein patients admitted to intensive care. Anaesthesia 2005, 60:16-21.

59. Christenson R: What is the value of B-type natriuretic peptide peptide testing for diagnosis, prognosis, or monitoring of the critically ill adult patients in intensive care? Clin Chem Lad Med 2008, 46(11):1524-1532.
60. Nishikimi T, Asakawa $H$, lida $H$, Matsushita $Y$, Shibasaki I: Different secretion patterns of two molecular forms of cardiac adrenomedullin in pressureand volume-overloaded human heart failure. J Card Fail 2004, 10:321-327.

61. Miyao Y, Nishikimi T, Goto Y, Miyazaki S, Daikoku S: Increased plasma adrenomedullin levels in patients with acute myocardial infarction in proportion to the clinical severity. Heart 1998, 79:39-44.

62. Kucher N, Goldhaber S: Cardiac biomarkers for risk stratification of patients with acute pulmonary embolus. Circulation 2003, 108:2191-2194.

63. La Vecchia L, Ottani F, Favero L, Spadaro G, Rubboli A, Boanno C: Increased cardiac troponin I on admission predicts inhospital mortality in acute pulmonary embolism. Heart 2004, 90:633-637.

64. Vuilleumier N, Le Gal G, Cornily C, Hochstrasser D, Bounameaux H Aujesky D, Righini M: Is N-terminal pro-brain natriureticpeptide superior to clinical scores for stratification in nonmassive pulmonary embolus? $J$ Thromb Haemost 2010, 8:1433-1435.

65. European Heart Journal: Guidelines on the diagnosis and management of acute pulmonary embolism The Task Force for the Diagnosis and Management of Acute Pulmonary Embolism of the European Society of Cardiology (ESC). Eur Heart J 2008, 29:2276-2315.

66. Lankeit $\mathrm{M}$, Konstantinides $\mathrm{S}$ : Mortality risk assessment and the role of thrombolysis in pulmonary embolus. Clin Chest Med 2010, 31:759-769.

67. Puls M, Dellas C, Lankeit M: Elevated heart-type fatty acid binding protein levels on admission predicts an adverse outcome in normotensive patients with acute pulmonary embolus. Eur Heart J 2007, 28:224-229.

68. Boscheri A, Wunderlich C, Langer M, Schoen S, Wiedermann B, Stolte D, Elmer G, Barthel P, Strasser R: Correlation of heart-type fatty acid-binding protein with mortality and echocardiographic data in patients with pulmonary embolism at intermediate risk. Am Heart J 2010, 160:294-300

69. Turner A, Tsamitros M, Bellomo R: Myocardial cell injury in septic shock. Crit Care Med 1999, 27:1775-1780

70. Agewall S, Giannitsis E, Jernberg T, Ka H: Troponin elevation in coronary vs. non-coronary disease. Eur Heart J 2011, 32:404-411.

71. Bouhemad B, Nicolas-Robin A, Arbelot C, Arthaud M, Feger F, Rouby JJ: Isolated and reversible impairment of ventricular relaxation in patients with septic shock. Crit Care Med 2008, 36(3):766-774.

72. ver Elst K, Spapen H, Nguyen D, Garbar C, Huyghens L, Gorus F: Cardiac troponins I and T are biological markers of left ventricular dysfunction in septic shock. Clin Chem 2000, 46(5):650-657.

73. Rosjo H, Varpula M, Hagve T, Karlsson S, Ruokonen E, Pettila V, Omland T: Circulating high sensitivity troponin $\mathrm{T}$ in severe sepsis and septic shock: distribution, associated factors, and relation to outcomes. Intensive Care Med 2011, 37:77-85.

74. Post F, Weilemann L, Messow C, Sinning C, Munze IT: B-type natriuretic peptide as a marker for sepsis-induced myocardial depression in intensive care patients. Crit Care Med 2008, 36:3030-3037.

75. Nellessen U, Goder S, Schobre R, Abawi M, Hecker H, et al: Serial analysis of troponin I levels in patients with ischemic and nonischemic dilated cardiomyopathy. Clin Cardiol 2006, 29:219-224.

76. Wallace TW, Abdullah SM, Drazner MH, Das SR, Khera A: Prevalence and determinants of troponin T elevation in the general population. Circulation 2006, 113(16):1958-1965.

77. Liu Z, Cui L, Wang Y, Guo Y: Cardiac troponin I and ventricular arrhythmia in patients with chronic heart failure. Eur J Clin Invest 2006, 36:466-472

78. Latini R, Masson S, Anand IS, Missov E, Carlson M: Prognostic value of very low plasma concentrations of troponin $\mathrm{T}$ in patients with stable chronic heart failure. Circulation 2007, 116:1242-1249.

79. Masson S, Latini R, Anand I: An update on cardiac troponins as circulating biomarkers in heart failure. Curr Heart Fail Rep 2010, 7:15-21.

80. Wu A, Jaffe A, Apple F, Jesse R, Francis G, Morrow D, Newby L, Ravkilde J, Tang W, Christenson R, NACB Committee, Cannon C, Storrow A: National Academy of Clinical Biochemistry laboratory medicine practice guidelines: use of cardiac troponin and B-type natriuretic peptide or Nterminal proB-type natriuretic peptide for etiologies other than acute coronary syndromes and heart failure. Clin Chem 2007, 53:2086-2096.

81. Jacobs L, van de Kerkhof J, Mingels A, Kleijnen V, van der Sande F, Wodzig W, Kooman J, van Dieijen-Visser M: Haemodialysis patients longitudinally assessed by highly sensitive cardiac troponin $\mathrm{T}$ and commercial cardiac troponin T and cardiac troponin I assays. Ann Clin Biochem 2009, 46:283-290. 
82. Hickman P, McGill D, Talaulikar G, Hiremagalur B, Bromley J, Rahman A, Koerbin G, Southcott E, Potter J: Prognostic efficacy of cardiac biomarkers for mortality in dialysis patients. Int Med 2009, 39:812-818

83. Rana R, Vlahakis N, Daniels: B-type Natriuretic peptide in the assessment of acute lung injury and cardiogenic pulmonary edema. Crit Care Med 2006, 34:1941-1946.

84. Mueller C, Maisel A, Mebazza A, Fillippatos G: The use of b-type natriuretic peptides in the intensive care unit. Congest Heart Failure 2008, 14(4 suppl 1):43-45.

85. Zapata L, Vera P, Roglan A, Gich I, Ordonez-Llanos J, Betbese A: B-type natriuretic peptide for prediction and diagnosis of weaning failure from cardiac origin. Intensive Care Med 2011, 37:477-485.

86. Mekontso-Dessap A, de Prost N, Girou E, Braconnier F, Lemaire F, BrunBuisson C, Brochard L: B-type natriuretic peptide and weaning from mechanical ventilation. Intensive Care Med 2006, 32(10):1529-1536.

87. Sinha M, Roy D, Gaze D, Collinson P, Kaski J: Role of 'ischaemia modified albumin,' a new biochemical marker of myocardial ischaemia, in the early diagnosis of acute coronary syndromes. Emerg Med 2004, 29:29-34.

88. Apple F, Smith S, Pearce L, Murakami M: Assessment of the multiplebiomarker approach for diagnosis of myocardial infarction in patients presenting with symptoms suggestive of acute coronary syndrome. Clin Chem 2009, 55:93-100

89. Slater M: The use of multi-cardaic biomarker panel in the intensive care unit: a prospective study [Med Hon Thesis] Sydney University Medical School; 2009.

90. Núñez J, Sanchis J, Bodí V, Fonarow G, Núñez E, Bertomeu-González V, Miñana G, Consuegra L, José Bosch M, Carratalá A, Chorro F, Llàcer A: Improvement in risk stratification with the combination of the tumour marker antigen carbohydrate 125 and brain natriuretic peptide in patients with acute heart failure. Eur Heart J 2010, 31:1752-1763.

91. Small E, Frost R, Olson E: MicroRNAs add a new dimension to cardiovascular disease. Circulation 2010, 121:1022-1032.

92. Fichtlscherer S, Rosa S, Fox H: Circulating MicroRNAs in patients with coronary artery disease. Circ Res 2010, 107:677-684.

93. Contu R, Latronico M, Condorelli G: Circulating MicroRNAs as potentia biomarkers of coronary artery disease-a promise to be fulfilled? Circ Res 2010, 107:573-574

94. Bartel D: MicroRNAs: genomics, biogenesis, mechanism, and function. Cell 2004, 116:281-297.

95. Wang G-K, Zhu J, Zhang J-T, Li Q, Li Y, He J, Qin Y, Jing Q: Circulating microRNA: a novel potential biomarker for early diagnosis of acute myocardial infarction in humans. Eur Heart J 2010, 31:659-666.

96. Alessandra Y, Devanna P, Limana F, Straino S: Circulating microRNAs are new and sensitive biomarkers of myocardial infarction. Eur Heart J 2010 31:2765-2773.

97. Condorelli G, Latronico M, Dorn G: MicroRNAs in heart disease: putative novel therapeutic targets? Eur Heart J 2010, 31:649-658.

doi:10.1186/2110-5820-2-8

Cite this article as: McLean and Huang: Cardiac biomarkers in the intensive care unit. Annals of Intensive Care 2012 2:8.

\section{Submit your manuscript to a SpringerOpen ${ }^{\circ}$ journal and benefit from:}

- Convenient online submission

- Rigorous peer review

- Immediate publication on acceptance

- Open access: articles freely available online

- High visibility within the field

- Retaining the copyright to your article

Submit your next manuscript at $>$ springeropen.com 